\title{
Experimental Focal Segmental Glomerulosclerosis: Correlation with Protein Excretion, Glomerular Filtration Rate, and Renal Plasma Flow
}

\author{
MANJU CHANDRA, MYRON SUSIN, SAUL TEICHBERG, AND MELINDA McVICAR \\ Department of Pediatrics and Laboratories, North Shore University Hospital, Manhasset, New York 11030 and \\ Department of Pediatrics and Pathology, Cornell University Medical College, New York, New York 10021
}

\begin{abstract}
A rat model of focal segmental glomerulosclerosis (FSGS) produced by repeated injections of aminonucleoside (AMN) of puromycin was used to evaluate the relative roles of hemodynamic alterations and AMN-induced glomerular visceral epithelial cell injury in the development of FSGS.

Twenty rats received three intraperitoneal injections of AMN on days 1, 21, and 28 and developed significant proteinuria. On day 50, 14 rats (group 1) underwent selective left renal perfusion with AMN and six rats (group 2) received left renal perfusion with saline. At sacrifice on day 70 or 110, group 2 rats had similar values in left and right kidneys for glomerular filtration rate (GFR), effective renal plasma flow (ERPF), and the amount of FSGS (13.1 $\pm 5.6 \%$ in left and $12.9 \pm 7.8 \%$ in right). In contrast, group 1 rats manifested a significantly higher amount of FSGS in right kidneys as compared to left kidneys $(3.1 \pm 1.3 \%$ in left and $6.3 \pm 2.0 \%$ in right, as well as significantly diminished GFR and ERPF in left as compared to right kidneys. A higher degree of FSGS was seen in kidneys with a higher GFR and ERPF. A positive correlation was observed between the mean 24-h protein excretion of the rats and the percentage of FSGS in left and right kidneys $(r=0.66, p<0.01)$. (Pediatr Res 18:1195-1201, 1984)
\end{abstract}

\section{Abbreviations}

FSGS, focal segmental glomerulosclerosis

AMN, aminonucleoside

ERPF, effective renal plasma flow

GFR, glomerular filtration rate

Idiopathic nephrotic syndrome associated with FSGS is characterized by resistance to steroid therapy, frequent progression to end stage renal disease, and recurrence in the transplanted kidney (5). The etiological factors and the pathogenic mechanisms for the development of proteinuria as well as the lesion of FSGS are not fully understood.

Several studies have pointed to the contribution of hemodynamic changes and increased filtration of proteins in the genesis

Received February 8, 1983; accepted May 10, 1984

Correspondence may be addressed to Manju Chandra, M.D., Division of Pediatric Nephrology, North Shore University Hospital, 300 Community Drive, Manhasset, NY 11030.

This work appeared in abstract form in Pediatric Research $(15: 691,1981)$. of FSGS $(3,8,11,13,19)$. Proteinuria has been shown to precede the development of focal sclerotic lesions in animal models of FSGS $(6,12)$. Glasser et al. (7) and Velosa et al. (20) produced chronic proteinuria and progressive FSGS in rats by repeated injections of the aminonucleoside of puromycin. These authors proposed that irreversible glomerular epithelial injury from a direct toxic effect of AMN was the primary event leading to proteinuria and development of FSGS. They observed a higher incidence of FSGS in rats who received AMN following unilateral nephrectomy $(7,20)$. The increase in FSGS following uninephrectomy could have been a result of 1) a higher dose of AMN reaching the single kidney and leading to greater epithelial cell injury or 2) the effects of increased blood flow and increased glomerular capillary pressure in the solitary kidney as suggested in several earlier studies $(3,8,11,19)$. The present study was designed to examine the relative roles of direct epithelial cell injury and alterations in renal plasma flow and GFR in the pathogenesis of FSGS produced by repeated administration of AMN in rats.

\section{MATERIALS AND METHODS}

The experimental design is outlined in Figure 1. Twenty male Sprague-Dawley rats weighing 75-100 gm were divided into two groups. An intraperitoneal injection of AMN (Nutritional Biochemicals Corporation, Cleveland, $\mathrm{OH}) 15 \mathrm{mg} / 100 \mathrm{~g}$ body weight in $1.0 \mathrm{ml}$ of normal saline, was administered to all animals on day 1. Intraperitoneal injections of AMN were repeated on days 21 and 28 at a dose of $5 \mathrm{mg} / 100 \mathrm{~g}$ body weight. On day 50 , in 14 rats (group 1), the left kidneys were selectively perfused with $15 \mathrm{mg}$ of $A M N$ in a volume of $1.5 \mathrm{ml}$ of normal saline, by the technique of Hoyer et al. (9). In six control rats (group 2), left kidneys were perfused with $1.5 \mathrm{ml}$ of normal saline.

Ten animals of group 1 and four animals of group 2 underwent renal function studies on day 110 and were then sacrificed. Four animals of group 1 and two animals of group 2 underwent split renal function studies on day 70 . After sacrifice, the kidneys of all animals were weighed and preserved for histological evaluation. Initially, day 110 was chosen for sacrifice, to allow 60 days after the selective left renal perfusion for histologic changes to manifest. When the initial study revealed a lesser degree of FSGS as well as lesser GFR and ERPF in left kidneys, we elected to study a few animals on day 70 to evaluate the alterations in renal function at an earlier time after perfusion. In this way, we wished to clarify whether the differences in renal function observed between left and right kidneys on day 110 were the result of established histologic lesions or whether these differences themselves influenced the development of the histologic lesions. 


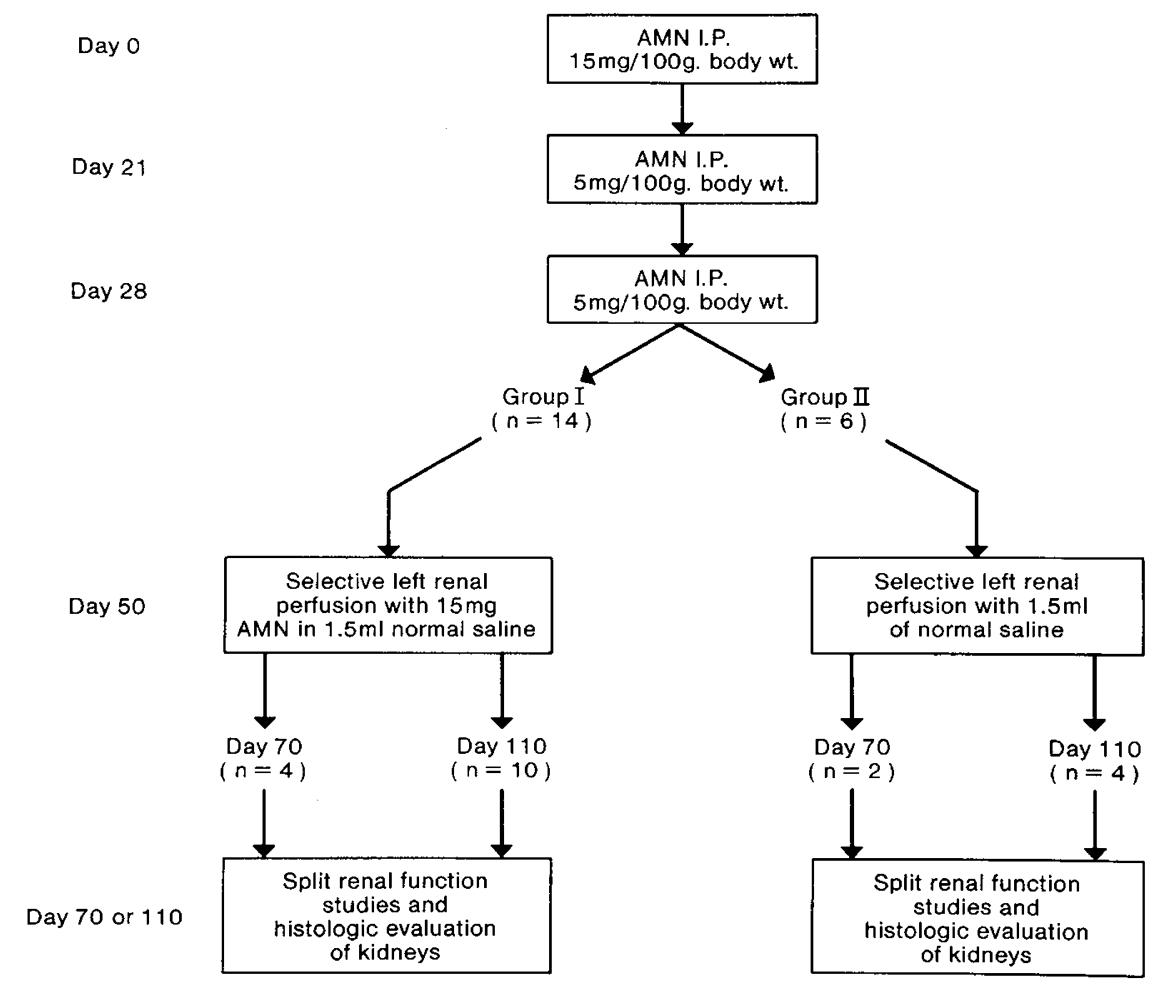

AMN = Aminonucleoside of puromycin

I.P. = Intraperitoneal injection

Fig. 1. Flow diagram of experimental design.

Twenty-four-hour urine collections were obtained from all rats in metabolic cages for an initial control period and then twice weekly during the course of the experiment. During collection periods, the rats were allowed ad libitum access to water, but no food. Thymol crystals were added to the urine collection flasks and aliquots were kept at $4^{\circ} \mathrm{C}$ until assayed for protein within 1 wk of collection. Urinary protein was measured by the method of Lowry et al. (14). To determine the mean total protein excretion during the entire experimental period of either 70 or 110 days, the 24-h protein excretion measured in each of the urine collections was totaled and this value was divided by the number of collected specimens. The results are expressed as mean protein excretion per $24 \mathrm{~h}$.

For the unilateral renal perfusion, the technique described by Hoyer et al. was used (9). Rats were anesthetized with pentobarbital and the abdominal cavity was exposed through a midline incision. The small vessels arising from the aorta in the vicinity of the left kidney were tied and cut in order to mobilize the aorta. A Lee microvascular clamp was then placed across the left renal vein and across the aorta above and below the left renal artery, thus totally isolating the left kidney from systemic circulation except for minor collaterals around the left ureter. A hole was punctured in the anterior wall of the left renal vein with a No. 20 gauge needle. Cotton $4 \times 6$ inch gauze sponges were placed in the abdominal cavity to absorb the effluent from the left renal vein and to avoid systemic absorption of the solution used. Normal saline $(1.5 \mathrm{ml})$ or saline solution containing AMN was injected via the clamped portion of the aorta into the left renal artery over a 15-20-s period. Seven minutes later, the kidney was reperfused with $4 \mathrm{ml}$ of saline and the holes in the aorta and renal vein were repaired. The renal vascular clamp was removed after a left renal ischemia time of exactly $15 \mathrm{~min}$. The abdomen was closed in two layers.

The surgical technique of unilateral renal perfusion involves a fair amount of dissection around the aorta and inferior vena cava and requires considerable surgical skill. The technique results in significant mortality even when previously healthy animals are used (4). We lost several animals during perfusion since animals were sick and toxic from previous administration of AMN. The 20 rats reported in this study are the animals who survived the unilateral renal perfusion and in whom no evidence of renal infarction was observed prior to closure of the abdomen.

Renal function studies were performed under anesthesia with pentobarbital $(5 \mathrm{mg} / 100 \mathrm{~g}$ body weight) given intraperitoneally. The jugular vein was cannulated with PE 50 tubing and both ureters were catheterized using PE 10 tubing. Normal saline equivalent to $1 \%$ of body weight was infused over $5 \mathrm{~min}$ to replace surgical fluid losses. This priming infusion contained 75 $\mathrm{mg}$ of mannitol, $2.5 \mu \mathrm{Ci}$ of sodium [ ${ }^{125} \mathrm{r}$ ]iothalamate (GlofilAbbot Inc., Chicago, IL), and $5 \mu \mathrm{Ci}$ of sodium ortho $\left[{ }^{13 !} \mathrm{I}\right]$ iodohippurate (Hippuran-Mallinckrodt, Inc., St. Louis, MO). This was followed by a sustaining infusion of normal saline at a rate of $0.2 \mathrm{ml} / \mathrm{min}$ which delivered sodium io[ [ $\left.{ }^{125} \mathrm{I}\right]$ thalamate, $5 \mu \mathrm{Ci} /$ $\mathrm{h}$; orthoiodo $\left[{ }^{131} \mathrm{I}\right] \mathrm{hippurate}, 10 \mu \mathrm{Ci} / \mathrm{h}$; and mannitol, $150 \mathrm{mg} / \mathrm{h}$. Thirty minutes were allowed for equilibration in the extracellular fluid before beginning urine collections. Three serial urine collections of 20-30-min duration were obtained. Blood samples (approximately $100 \mu \mathrm{l}$ ) were taken from the warmed tail vein at the midpoint of the urine collection periods. At the completion of the experiment, both kidneys were removed and weighed.

The counts of orthoiodo ${ }^{131}$ I $]$ hippurate and sodium [ ${ }^{125}$ I] thalamate in the urine and serum were measured in a scintillation counter (Packard Auto Y scintillation spectrometer, model 5130) using appropriate spectrometer settings for each radionuclidę. The contribution of cross-talk of the photo energies used was determined by standard double isotope technique. GFR and ERPF were derived from the clearance of sodium io[ $\left.{ }^{125} \mathrm{I}\right]$ thalamate and orthoiodo[ $\left.{ }^{131} \mathrm{I}\right]$ hippurate, respectively.

An attempt was made to measure protein concentration in the urine samples obtained from each ureter. However urine flow rate was low in several animals and prolonged urine collection periods would have been required. Since prolonged anesthesia 
may influence the circulatory status and renal function, we elected to forego urine protein determinations in favor of obtaining accurate estimates of GFR and ERPF.

Kidneys from all of the experimental rats and from four agematched normal control rats were examined by light microscopy. Kidneys were sliced longitudinally so that each slice contained cortex, medulla, and pyramids. Renal tissue was fixed in buffered formalin of $\mathrm{pH}$ 7.3. At least 200 glomeruli from each kidney were examined for evidence of glomerulosclerosis. Electron microscopic studies were performed in four normal control rats, four rats of group 1, and two rats of group 2. Kidney tissue containing cortex and medulla was fixed by immersion in $2.5 \%$ glutaraldehyde in $0.1 \mathrm{M}$ sodium cacodylate buffer $(\mathrm{pH} 7.3)$ for 2 $\mathrm{h}$, rinsed overnight in $0.1 \mathrm{M}$ sodium cacodylate buffer with $7 \%$ sucrose, postfixed in osmium tetroxide for $1 \mathrm{~h}$, dehydrated in graded series of ethanols, and embedded in Epon. Thin sections were cut on a Porter-Blum MT 2-B ultramicrotome and examined on a JEOL JEM-100 electron microscope. Electron micrographs were taken at an initial magnification of $\times 4,000-15,000$.

The paired $t$ test was used to compare differences between left and right kidneys. $p$ values were computed from the $t$ value derived from formula $t=D / S D$ where $D$ is the mean difference of left and right kidney function and $S$, the estimate of standard error of $D$. The 0.01 level of probability (two-tailed) was used as the criterion of significance.

\section{RESULTS}

Urinary Protein Excretion. The initial control protein excretion of group 1 and group 2 rats prior to the first injection of
AMN was $3.2 \pm 0.5 \mathrm{mg} / 24 \mathrm{~h}$. All animals developed significant proteinuria within 4 days of the initial injection of AMN. This reached a peak by day 10 and then declined, but did not reach normal levels by day 21 . Significant proteinuria again developed in all rats following repeat injections of AMN on days 21 and 28 with gradual decline after day 35. A further increase in protein excretion in group 1 rats was noted in the $2 \mathrm{wk}$ following left renal perfusion with $\mathrm{AMN}$ on day 50 . Thereafter, proteinuria gradually declined. In group 2 rats, left renal perfusion with normal saline caused no alteration in protein excretion. The magnitude of proteinuria differed greatly among individual rats, reflecting heterogeneity in their response to AMN injections. Animals who manifested a lesser degree of proteinuria after the first injection of $\mathrm{AMN}$ did so following the subsequent injections as well. On the other hand, animals who manifested greater degrees of proteinuria initially continued to excrete large amounts of protein.

Renal Morphology and Occurrence of FSGS. Normal controls. Histologic examination of the glomeruli from four normal control rats revealed no evidence of FSGS or tubulointerstitial changes (Table 1). Electron microscopy revealed normal glomerular basement membranes and glomerular visceral epithelial cells. The mesangium was normocellular, matrix was not increased, and no deposits were present.

Group 1. In group 1 rats, the left kidneys were noted to be uniformly lower in weight than the right kidneys $(p<0.001)$. FSGS was observed in 10 animals. The percentage of FSGS was paradoxically significantly higher in right kidneys $(6.3 \pm 2.0 \%)$ which did not receive additional perfusion with $\mathrm{AMN}$, as compared to left kidneys $(3.1 \pm 1.3 \%)(p<0.01)$. The magnitude of

Table 1 . Correlation of mean urinary protein excretion with renal morphology

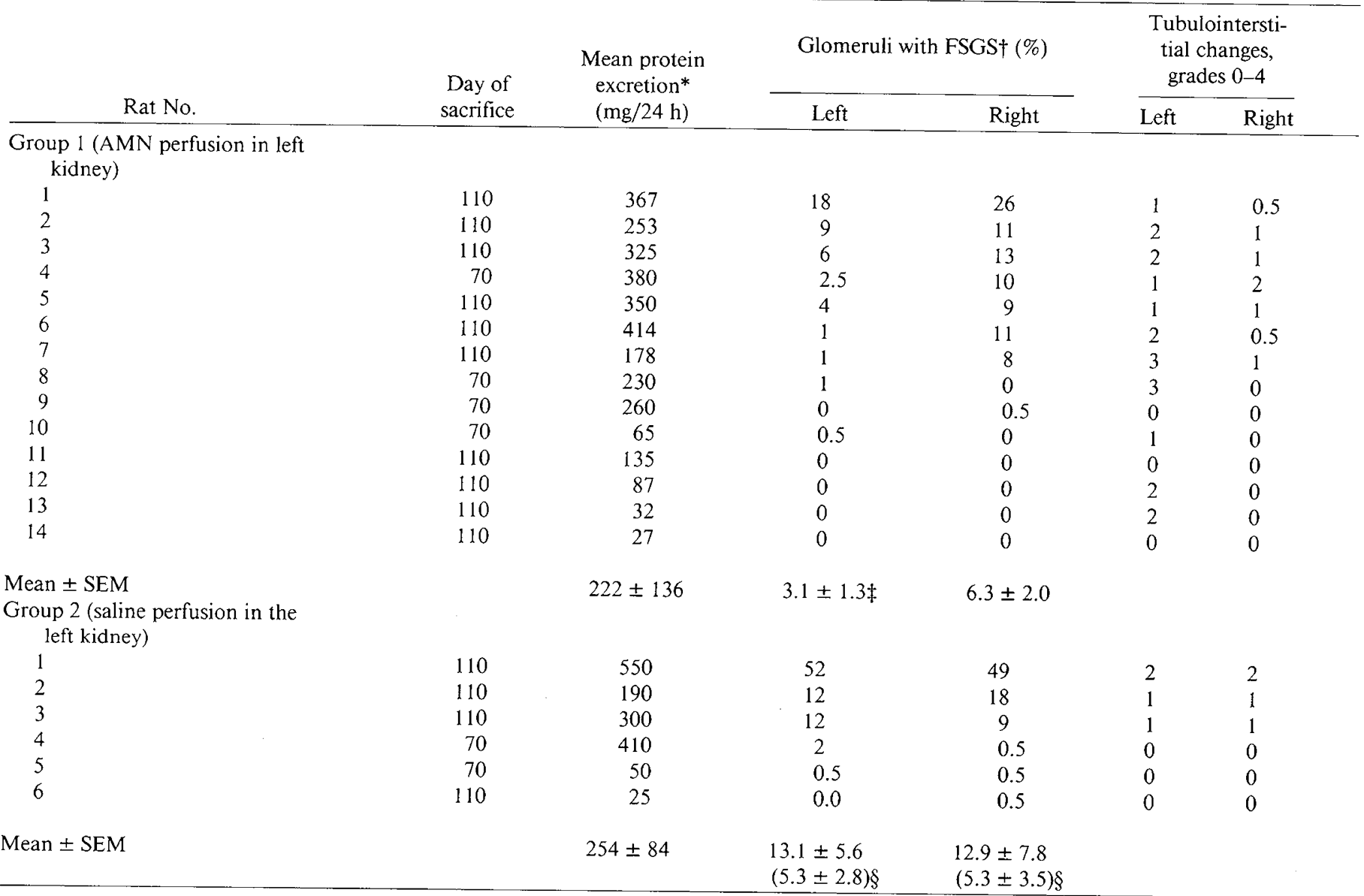

* Mean protein excretion represents total measured 24-h protein excretion divided by the number of collected specimens.

+ Correlation coefficient for mean protein excretion versus \%FSGS in left and right kidney of each animal $(r=0.66, p<0.01)$.

$\$ p$ (left-right) $<0.01$; see text for derivation of $p$ value.

$\S$ Mean \pm SEM of group 2 after exclusion of rat 1 which manifested unusually extensive FSGS. 
FSGS differed greatly among animals. However, the right kidney consistently manifested a higher percentage of FSGS than left except in rat 10 where $0.5 \%$ of the glomeruli in the left kidney manifested FSGS versus none in the right kidney. Focal glomerular sclerotic lesions were characterized by collapse and obliteration of capillary walls as well as expansion of the mesangium due to an increase in periodic acid Schiff-positive material, subendothelial hyaline deposits, and adhesions of the glomerular tuft to Bowman's capsule (Fig. 2). Tubulointerstitial changes consisting of focal tubular atrophy and interstitial mononuclear infiltrates (grades $0-4$ ) were present in the left kidneys of 11 rats and right kidneys of seven rats.

On electron microscopic examination, glomeruli showing segmentally' sclerotic lesions were remarkable for capillary wall collapse, extensive foot process obliteration, and epithelial cell detachment. A loose fibrillar material was found within the space between the detached epithelial cells and the glomerular basement membrane (Fig. 3). The glomerular basement membranes were irregularly thickened and the capillary lumens were narrowed by mesangial cell ingrowth (Fig. 4). Sections from glomeruli showing minimal changes demonstrated only segmental effacement of epithelial cell foot processes.

Group 2. Group 2 rats had left and right kidneys of equal weight. FSGS was noted in six of six animals and was of equal magnitude in right and left kidneys. Rat 1 manifested more extensive FSGS than other animals and this accounted for a greater severity of FSGS observed in group 2 rats as compared to group 1 rats. When rat 1 was excluded from the statistical calculations for FSGS, the magnitude of FSGS was similar in group 1 and group 2. Electron microscopy revealed changes in sclerotic glomeruli which were similar to those observed in group 1 rats.

A positive correlation was observed between the mean protein excretion and the percentage of glomeruli showing FSGS $(r=$ $0.66, p<0.01$ ). Rats with mean protein excretion of less than $178 \mathrm{mg} / 24 \mathrm{~h}$ either did not develop FSGS at all or manifested
FSGS in no more than $0.5 \%$ of glomeruli (Table 1). All animals with mean protein excretion greater than $178 \mathrm{mg} / 24 \mathrm{~h}$ developed FSGS in $1 \%$ or more of their glomeruli. The greatest degree of FSGS was observed in rat 1 of group 2 who also manifested the highest protein excretion. Age-matched control rats did not manifest any glomerulosclerosis.

Renal Function Studies. Results obtained from rats studied on day 70 or 110 have been combined in Table 2 since the clearance values of sodium iothalmate and orthoiodohippurate were not significantly different on day 70 as compared to day 110 .

Group 1. Left kidneys weighed significantly less than right kidneys $(p<0.001)$ in group 1 rats. GFR and ERPF were significantly decreased in the left kidneys which received an additional perfusion with $\mathrm{AMN}$ as compared to the right kidneys $(p<0.01)$. GFR and ERPF, however, were not different between right and left side when absolute values were corrected for kidney weight. Mean GFR and ERPF of three rats studied on day 70 were not significantly different from that of seven animals studied on day 110 . On day 70 , mean GFR was $818 \pm 384 \mu \mathrm{l} / \mathrm{min}$ on the left and $1915 \pm 328 \mu \mathrm{l} / \mathrm{min}$ on the right side while on day 110 , GFR was $1021 \pm 170 \mu \mathrm{l} / \mathrm{min}$ on the left side and $1515 \pm$ 291 on the right side. ERPF was $2685 \pm 1434 \mu \mathrm{l} / \mathrm{min}$ on the left and $4663 \pm 795 \mu \mathrm{l} / \mathrm{min}$ on the right on day 70 , while on day 110 , ERPF was $1945 \pm 315 \mu \mathrm{l} / \mathrm{min}$ on the left and $2968 \pm 532$ $\mu \mathrm{l} / \mathrm{min}$ on the right.

Group 2. The kidney weight, GFR, and ERPF were similar in group 2 rats in the saline-perfused left kidneys and contralateral right kidneys on day 70 as well as on day 110 .

\section{DISCUSSION}

Our studies confirm the observations of Glasser et al. (7) that repeated administration of AMN in rats leads to the development of FSGS. In our study, a positive correlation was observed between the mean urinary protein excretion and the magnitude of FSGS in the animals. FSGS involving more than $1 \%$ of

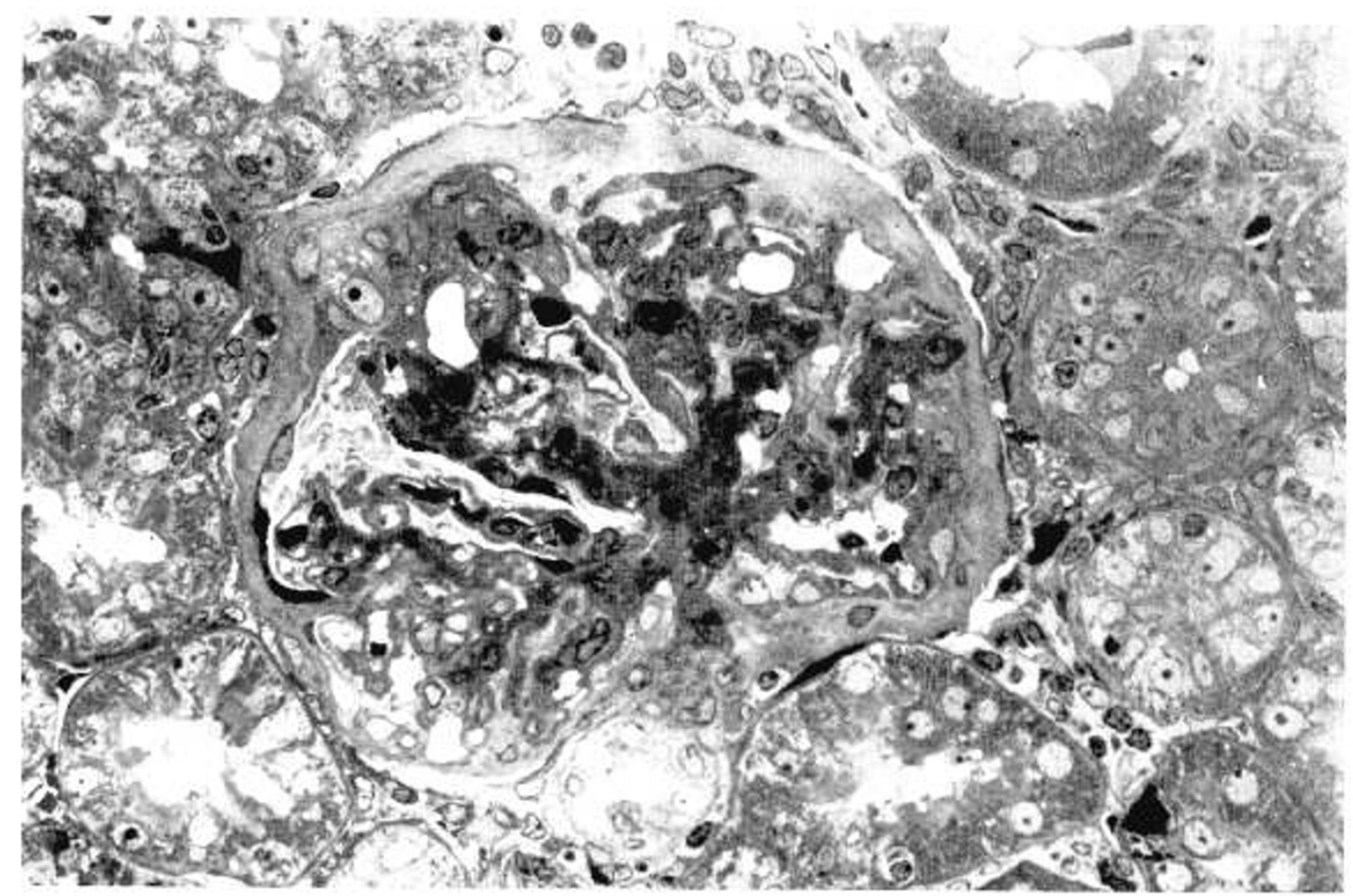

Fig. 2. Light photomicrograph of rat glomerulus showing segmental capillary wall collapse with sclerosis and adhesions to thickened Bowman's capsule (plastic embedded toluidine blue stain $\times 540$ ). 


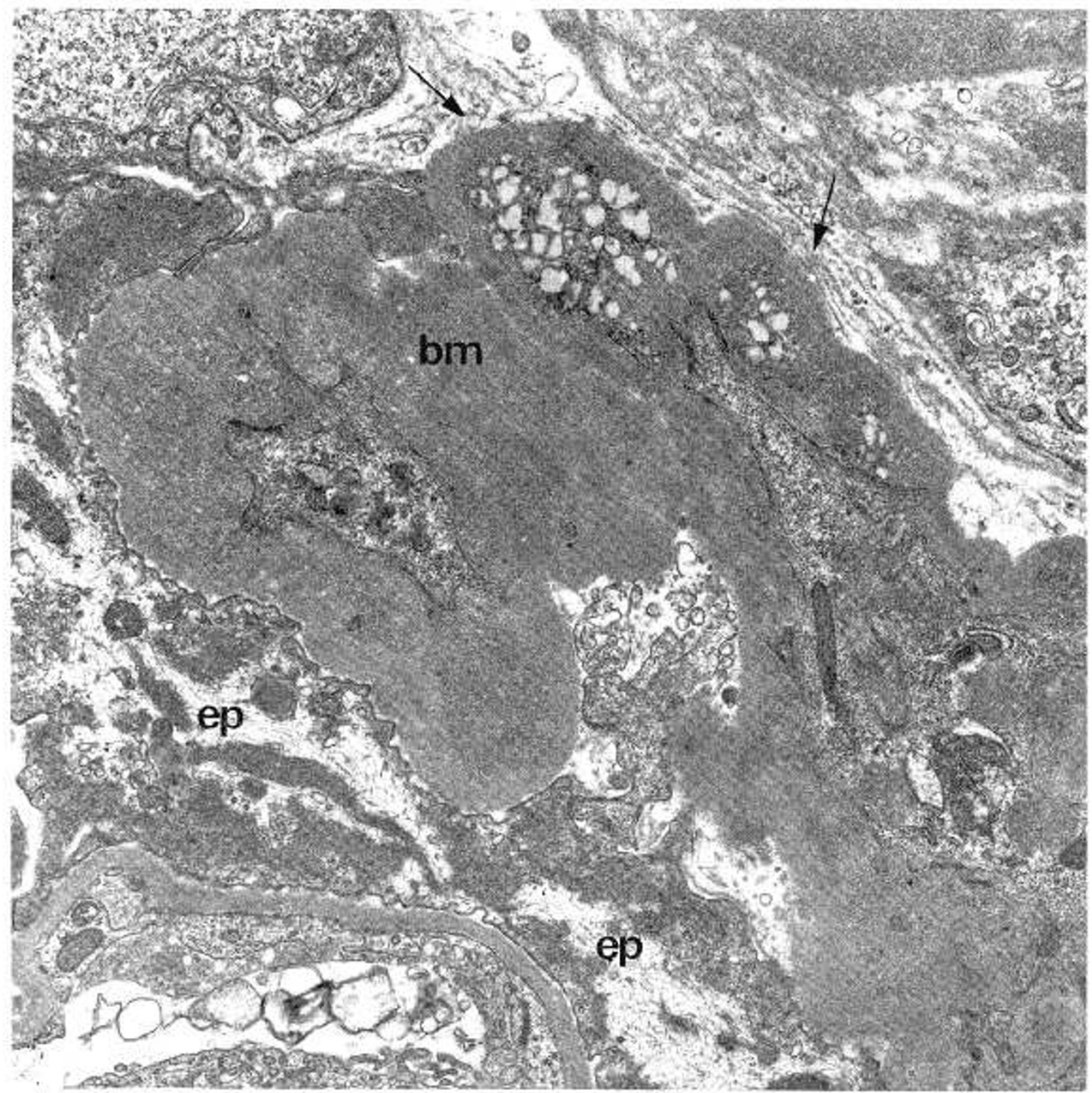

Fig. 3. Electron micrograph of portion of glomerular capillary wall from glomerulus in Figure 2 showing collapsed basement membrane $(b m)$. The capillary lumen is obliterated. The basement membrane is focally denuded of epithelium and the intervening space is filled with loose fibrillar material (arrows). Epithelial cell foot processes $(e p)$ are extensively effaced in the lower half of the field $(\times 10,500)$.

glomeruli was observed only in animals in whom urinary protein excretion over the course of the experiment was above a threshold value. This observation suggests either that proteinuria itself plays a pathogenetic role in the causation of FSGS or that proteinuria is an epiphenomenon of the underlying epithelial injury or dysfunction, which leads to segmental sclerosis of the glomerular tuft.

Electron microscopic examination in our rats showed detachment of glomerular visceral epithelial cells from glomerular basement membrane and extensive effacement of epithelial cell foot processes in the glomeruli which manifested segmental sclerosis, indicating the presence of damage to the visceral epithelial cells. Other investigators have reported similar changes in rats following acute and chronic administration of $\operatorname{AMN}(1,18)$. Persistent injury to glomerular epithelium is believed to result in proteinuria due to a diminution in the electrostatic barrier function of the glomerular capillary wall $(2,20)$. An increase in glomerular capillary permeability has been shown to result not only in proteinuria, but also in an increased uptake and decreased clearance of proteins from the mesangium $(15,16)$. The accumulation of proteins and other macromolecules in the mesan- gium is thought to lead to mesangial cell injury, dysfunction, and glomerulosclerosis $(7,12,20)$.

We observed that the left kidneys of rats who received selective left renal perfusion with AMN (group 1) were smaller than right kidneys. This difference was most likely due to the diminished growth of left kidney in relation to a lower renal plasma flow rather than active atrophy, since the magnitude of glomerulosclerosis and interstitial atrophy in the left kidney was not indicative of a significant loss of renal tissue.

Unilateral renal perfusion with AMN in previously normal rats has been shown to result in significant alterations in renal function after 7 days. These are decrease in GFR, renal plasma flow, filtration fraction, and sodium excretion and increase in protein excretion from the AMN-perfused kidney as compared to the nonproteinuric contralateral kidney (4). Unilateral renal perfusion with saline did not alter renal function or protein excretion (4). Other investigators have observed a decrease in GFR and renal blood flow in both kidneys of rats following acute parenteral administration of AMN (2).

In the study reported by Glasser et al. (7) uninephrectomy enhanced the development of FSGS. This effect could result 


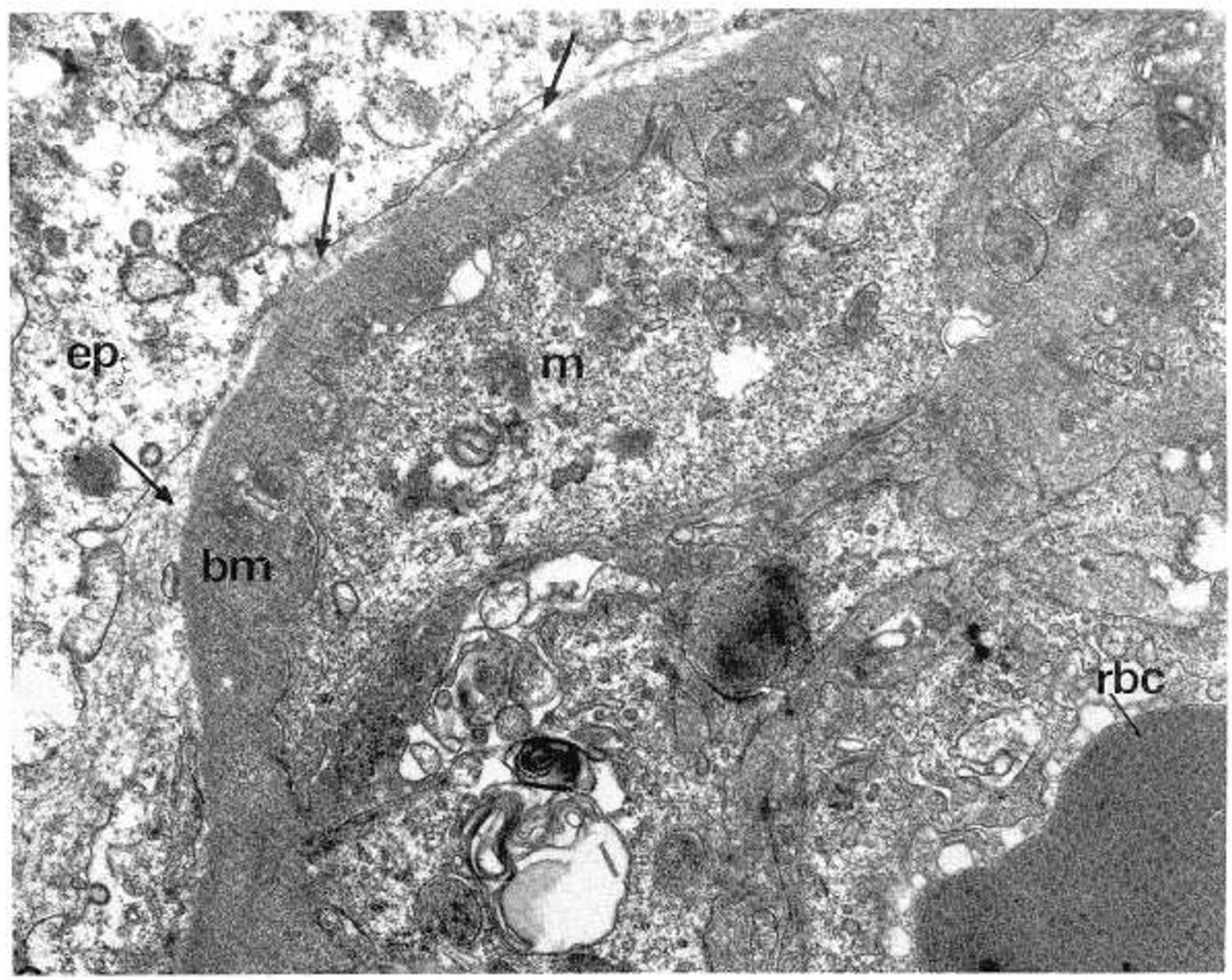

Fig. 4. Electron micrograph of portion of glomerular capillary wall from glomerulus in Figure 2. The glomerular basement membrane $(b m)$ is irregularly thickened associated with mesangial cell interposition $(m)$ narrowing the capillary lumen. Note the separation of epithelial cell cytoplasm from the basement membrane (arrows). $r b c$, red blood cell; $e p$, epithelial cell $(\times 14,000)$.

Table 2. Right and left kidney function of group 1 and 2 rats*

\begin{tabular}{|c|c|c|c|c|}
\hline & Left kidney & Right kidney & Left/right & $\begin{array}{l}p(\text { left }- \\
\text { right }) \dagger\end{array}$ \\
\hline \multicolumn{5}{|l|}{ Group 1} \\
\hline Kidney weight (g) & $1.82 \pm 0.2$ & $2.27 \pm 0.22$ & 0.44 & $<0.001$ \\
\hline $\mathrm{Cl}_{\text {iothalamate }}(\mu \mathrm{l} / \mathrm{min})$ & $840 \pm 169$ & $1635 \pm 224$ & 0.34 & $<0.01$ \\
\hline$C l_{\text {iothalamate }}(\mu \mathrm{l} / \mathrm{min} \cdot \mathrm{g}$ kidney $)$ & $613 \pm 118$ & $784 \pm 125$ & 0.44 & NS \\
\hline$C l_{\text {hippuran }}(\mu \mathrm{l} / \mathrm{min})$ & $2167 \pm 455$ & $3477 \pm 544$ & 0.38 & $<0.01$ \\
\hline$C l_{\text {hippuran }}(\mu \mathrm{l} / \mathrm{min} \cdot \mathrm{g}$ kidney $)$ & $1318 \pm 280$ & $1611 \pm 274$ & 0.45 & NS \\
\hline \multicolumn{5}{|l|}{ Group 2} \\
\hline Kidney weight $(\mathrm{g})$ & $1.98 \pm 0.16$ & $1.92 \pm 0.17$ & 0.51 & NS \\
\hline$C l_{\text {iothalamate }}(\mu \mathrm{l} / \mathrm{min})$ & $1662 \pm 64$ & $1498 \pm 496$ & 0.52 & NS \\
\hline$C l_{\text {iothalamate }}(\mu \mathrm{l} / \mathrm{min} \cdot \mathrm{g}$ kidney $)$ & $886 \pm 37$ & $742 \pm 130$ & 0.54 & NS \\
\hline$C l_{\text {hippuran }}(\mu \mathrm{l} / \mathrm{min})$ & $3396 \pm 96$ & $2731 \pm 305$ & 0.55 & NS \\
\hline$C l_{\text {hippuran }}(\mu \mathrm{l} / \mathrm{min} \cdot \mathrm{g}$ kidney $)$ & $1594 \pm 43$ & $1307 \pm 37$ & 0.55 & NS \\
\hline
\end{tabular}

* Results of measurements performed on days 70 and 110 have been combined. NS, not significant. Values are mean \pm SEM.

$\dagger$ See "Materials and Methods" for the derivation of $p$ value.

from enhanced blood flow to the single kidney or a higher dose of AMN reaching the solitary kidney and resulting in greater epithelial injury. The relative contribution of these two possibilities was analyzed in our study.

We observed that in animals with proteinuria induced by prior systemic administration of AMN, additional unilateral renal perfusion with AMN did not enhance the development of FSGS in the perfused kidney. On the contrary, the kidney which received additional exposure to AMN manifested fewer sclerotic glomeruli. The GFR and ERPF were significantly depressed in the AMN-perfused left kidney as compared to the right kidney of group 1 rats on day 70 as well as day 110 . In group 2, the GFR and ERPF were similar in left and right kidneys and so was the degree of FSGS in the two kidneys. The causative mechanism for the association of lesser GFR and ERPF to lesser degree of FSGS is not clear from our study.

Our data are in agreement with previous studies which have emphasized the role of hemodynamic changes in the genesis of FSGS (3, 8, 11, 13, 19). Unilateral nephrectomy has been observed to hasten the progression of spontaneously occurring 
FSGS in aging rats (13) as well as accelerate FSGS induced by a variety of agents $(3,7,19,21)$. The adaptive sustained increase in single nephron GFR, glomerular plasma flow, and transcapillary hydraulic pressure gradient in the remnant nephrons has been postulated to be responsible for the enhancement in glomerulosclerosis after renal ablation $(3,8)$. Increased dietary protein intake has been shown to accelerate the development of FSGS in uninephrectomized rats (13) and dietary protein restriction has been found to have an ameliorative effect on the development of glomerulosclerosis in experimental models of renal injury $(13,21)$. Protein-rich meals have been demonstrated to increase renal blood flow and GFR (17) and dietary protein restriction results in a reduction in GFR (10). These studies indicate that alterations in renal hemodynamics can modify the extent of glomerular damage.

Our study design has allowed us to dissociate the effects of glomerular epithelial injury secondary to AMN from those of alterations in GFR and ERPF in the pathogenesis of FSGS in rats with $A M N$-induced chronic proteinuria. We observed that AMN-induced glomerular visceral epithelial cell injury per se does not lead to the sclerosis of the corresponding glomerular tuft, since the kidney which received a higher dose of AMN manifested less FSGS. We have demonstrated that unilateral decrease in GFR and effective renal plasma flow is associated with lesser development of FSGS in the ipsilateral kidney, even when an increase in glomerular capillary permeability to protein is present.

Acknowledgments. The authors thank J. R. Hoyer, M.D. of Harbor General Hospital, Torrance, CA and R. A. Wapnir, Ph.D. of North Shore University Hospital for their many valuable suggestions.

\section{REFERENCES}

1. Andrews PM 1977 A scanning and transmission electron microscopic comparison of puromycin aminonucleoside-induced nephrosis to hyperalbuminuria induced proteinuria with emphasis on kidney podocyte pedical loss. Lab Invest 36:183

2. Bohrer MP, Baylis C, Robertson CR, Brenner BM 1977 Mechanism of the puromycin induced defects in the transglomerular passage of water and macromolecules. J Clin Invest 60:152
3. Brenner BM, Meyer TW, Hostetter T 1982 Dietary protein intake and the progressive nature of kidney disease: the role of hemodynamically mediated glomerular injury in the pathogenesis of progressive glomerular sclerosis in aging, renal ablation, and intrinsic renal disease. N Engl J Med 307:652

4. Chandra M, Hoyer JR, Lewy JE 1981 Renal function in rats with unilateral proteinuria produced by renal perfusion with aminonucleoside. Pediatr Res $15: 340$

5. Chandra M, Lewy JE, Mouradian J, Susin M, Hoyer JR 1981 Recurrent nephrotic syndrome with three successive renal allografts. Am J Nephrol $1: 110$

6. Couser WG, Stilmant MD 1975 Mesangial lesions and focal glomerular sclerosis in the aging rat. Lab Invest 33:491

7. Glasser RJ, Velosa JA, Michael AF 1977 Experimental model of focal sclerosis. I. Lab Invest 36:519

8. Hostetter TH, Olson JS, Rennke HG, Venkatchalem MA, Brenner BM 1981 Hyperfiltration in remnant nephrons: a potentially adverse response to renal ablation. Am J Physicians 10:F85

9. Hoyer JR, Mauer SM, Michael AF 1975 Unilateral renal disease in the rat. I. Clinical, morphologic and glomerular mesangial functional features of the experimental model produced by renal perfusion with the aminonucleoside of puromycin. J Lab Clin Med 85:756

10. Ichikawa I, Purkerson ML, Klahr S, Troy JL, Martinez-Maldonado M, Brenner BM 1980 Mechanism of reduced glomerular filtration rate in chronic malnutrition. J Clin Invest 65:982

11. Kiprov DD, Colvin RB, McClusky RT 1982 Focal and segmental glomerulosclerosis and proteinuria associated with unilateral renal agenesis. Lab Invest $46: 275$

12. Kreisberg JI, Karnovsky M 1978 Focal glomerular sclerosis in the fawn hooded rat. Am J Pathol 92:637

13. Lalich TJ, Burkholder DM, Paik WC 1975 Protein overload nephropathy in rats with unilateral nephrectomy. Arch Pathol 99:72

14. Lowry OH, Rosebrough NJ, Farr AL, Randall RJ 1951 Protein measurement with the Folin phenol reagent. J Biol Chem 193:265

15. Mauer SM, Fish AJ, Blau EB, Michael AF 1972 The glomerular mesangium I. Kinetic studies of macromolecular uptake in normal and nephrotic rats. $J$ Clin Invest 51:1092

16. Mauer SM, Fish AJ, Dayn NK, Michael AF 1974 The glomerular mesangium. II. Studies of macromolecular uptake in nephrotoxic nephritis in rats. J Clin Invest 53:431

17. O'Connor WJ, Summerill RA 1976 The effect of a meal of meat on glomerular filtration rate in dogs at normal urine flows. $J$ Physiol 256:81

18. Ryan GB, Karnovsky MJ 1975 An ultrastructural study of the mechanisms of proteinuria in aminonucleoside nephrosis. Kidney Int 8:219

19. Steffes MW, Brown DM, Mauer SM 1978 Diabetic glomerulopathy following unilateral nephrectomy in the rat. Diabetes 27:35

20. Velosa JA, Glasser RJ, Nevins TE, Michael AF 1977 Experimental model of focal sclerosis II. Lab Invest 36:527

21. Wachtel LN, Cole LJ, Rosen VJ 1966 X-ray induced glomerulosclerosis in rats: modification of lesion by food restriction, uninephrectomy, and age. $J$ Gerontol 21:442 